\title{
Clinical analysis of bevacizumab targeting therapy in treating early colorectal carcinoma after operation
}

\author{
TIE-LING LI ${ }^{1}$, ZHI-GUO SUN ${ }^{2}$, XIAOMING JIANG ${ }^{3}$ and HAI-FENG GUO ${ }^{2}$ \\ ${ }^{1}$ Pathological Staff Room, Mudanjiang Medical University, Mudanjiang, Heilongjiang 157011; \\ ${ }^{2}$ Normal Surgical Department, Hongqi Hospital, Mudanjiang Medical University, Mudanjiang, Heilongjiang 157000; \\ ${ }^{3}$ Department of Intensive Care Unit, Hongqi Hospital, Mudanjiang Medical University, \\ Mudanjiang, Heilongjiang 157011, P.R. China
}

Received September 12, 2016; Accepted February 21, 2017

DOI: $10.3892 / \mathrm{ol} .2017 .6087$

\begin{abstract}
Clinical effects of bevacizumab target therapy in treating early colorectal carcinoma (CRC) after resection were analyzed. Ninety-two patients diagnosed with early CRC and treated with endoscopic mucosal resection for the first time were selected for the study. They were randomly divided into the control group and the observation group with 46 cases in each group. Control group was administered the chemotherapy regimen with oxaliplatin, calcium folinate and 5-fluorouracil, while bevacizumab targeting therapy was given to the observation group. The follow-up median time in these two groups was 30 months. In the observation group, objective response rate and disease control rate were higher than those in the control group, the adverse reaction rate was lower, and the differences were statistically significant $(\mathrm{p}<0.05)$. In the observation group, disease-free survival was prolonged (38.6 vs. 30.5 months, $\mathrm{p}<0.05$ ); the recurrence rate was lower (13.0 vs. $30.4 \%, \mathrm{p}<0.05)$; the survival rate was improved (91.3 vs. $76.1 \%, \mathrm{p}<0.05)$. Vascular endothelial growth factor (VEGF) expressions of follow-up serum in these two groups were lower; VEGF expression in the observation group was lower than that in the control group, and the differences had statistical significance $(\mathrm{p}<0.05)$. There was no statistical significance in comparison of positive expression in tissue VEGF ( $p>0.05$ ). In conclusion, after bevacizumab targeting therapy in treating early CRC, VEGF expression of serum was significantly lower; treatment effects improved; adverse drug reaction was reduced; survival time was prolonged; the recurrence rate was reduced; the survival rate improved. It has good application values.
\end{abstract}

Correspondence to: Dr Hai-Feng Guo, Normal Surgical Department, Hongqi Hospital, Mudanjiang Medical University, 1 Taiping Road, Mudanjiang, Heilongjiang 157000, P.R. China

E-mail: haifengg6628@163.com

Key words: bevacizumab, early colorectal carcinoma, targeting therapy

\section{Introduction}

In China, the morbidity and mortality of colorectal carcinoma (CRC), are next only to lung and liver cancer, and increasing each year especially in younger population (1). The pathogenesis of CRC is related to bacterial and viral infection, immunological disorders, hereditary mechanisms, living habits, diet, hormonal abnormality, and weight (2). The genesis and development of CRC is a multi-genes evolution process, which is caused by vascular endothelial growth factor (VEGF), epidermal growth factor receptor (EGFR), tumor suppressor gene, proto-oncogene, abnormality of signal transduction and other molecular events. Treatment targeting molecular level is most promising (3). Bevacizumab is the first humanized monoclonal antibody used for inhibiting blood vessel growth. With endogenous VEGF competing for binding with VEGF receptor, it can limit tumor growth effectively and reduce chemotherapy resistance (4). Currently, it is effective as second-line or first line chemotherapy regimens in treating progressive CRC $(5,6)$. Endoscopic resection of early CRC and precancerous lesions has high success rate of resection (7), but there is no unified understanding on whether it is with chemotherapy combined or not. Clinical data from 5 -year follow-up suggest that lymph node metastasis rate is $20-40 \%$ (8) and early combined chemotherapy can improve survival outcomes (9). Based on this, we analyzed the application value of bevacizumab in the early stage and chemotherapy regimen containing 5-fluorouracil regularly in treating early CRC after laparoscopic surgery.

\section{Materials and methods}

General material. Ninety-two patients diagnosed with early CRC being admitted to Hongqi Hospital from January 2013 to January 2016 were included in the study. They were treated with endoscopic mucosal resection for the first time and diagnosis was confirmed pathologically. Patients with colorectal metastases, primary tumors in other parts, serious primary diseases, such as organ dysfunctions of heart, liver, lung, kidney and brain, incomplete clinical data, and other reasons were excluded. Our investigation obtained approval of the Ethics Committee of Hongqi Hospital and written informed 
Table I. Comparisons of treatment effects [cases, n (\%)].

\begin{tabular}{lccccccc}
\hline Groups & Cases & CR & PR & SD & PD & ORR & DCR \\
\hline Control & 46 & $25(54.3)$ & $7(15.2)$ & $4(8.7)$ & $10(21.7)$ & $32(69.6)$ & $36(78.3)$ \\
Observation & 46 & $32(69.6)$ & $8(17.4)$ & $3(6.5)$ & $3(6.5)$ & $40(87.0)$ & $43(93.5)$ \\
$\chi^{2}$ & & & & & & 4.089 & 4.389 \\
P-value & & & & & & 0.043 & 0.036 \\
\hline
\end{tabular}

$\mathrm{CR}$, complete remission; $\mathrm{PR}$, partial remission; $\mathrm{SD}$, stable disease; $\mathrm{PD}$, progressive disease; ORR, objective response rate; DCR, disease control rate.

consent of patients or their family was obtained. Patients were randomly divided into the control group and the observation with 46 cases each. In the control group, there were 25 males and 21 females with an average age of $52.6 \pm 10.3$ years. There were 28 cases of TNM stage I and 18 cases of stage II; there were 30 cases of adenocarcinoma, 14 cases of squamous cell carcinoma and 2 cases of others. Out of the total cases in control group 4 were of poor differentiation, 18 of moderate differentiation and 24 of high differentiation. The location was, 19 cases of colon and 27 cases of rectum, and the largest diameter of tumors was $0.5-2.6 \mathrm{~cm}$, and the average was $1.7 \pm 0.5 \mathrm{~cm}$; the average number of tumors is $1.2 \pm 0.3$. In the observation group, there were 23 males and 23 females with an average age of $53.6 \pm 12.4$ years. There were 26 cases of TNM stage I and 20 cases of stage II; 31 cases were of adenocarcinoma, 12 cases of squamous cell carcinoma and 3 cases of others. There were 5 cases of poor differentiation, 19 cases of moderate differentiation and 22 cases of high differentiation. Based on the location, there were 18 cases of colon and 28 cases of rectum, and the largest diameter of tumors was $0.6-3.0 \mathrm{~cm}$, and the average was $1.9 \pm 0.7 \mathrm{~cm}$; the average number of tumors is $1.3 \pm 0.4$. Baseline data of these two groups was comparable.

Research methods. The same surgical and nursing team treated both groups according to standard medical procedure. Endoscopic resection was completed in these two groups successfully, and surgical margin was pathologically confirmed as negative during the surgery. After the surgery, convention chemotherapy regimen was adopted in the control group as: $90 \mathrm{mg} / \mathrm{m}^{2}$ oxaliplatin in intravenous guttae (ivgtt) for $4 \mathrm{~h}, 300 \mathrm{mg} / \mathrm{m}^{2}$ calcium folinate in ivgtt for $2 \mathrm{~h}, 400 \mathrm{mg} / \mathrm{m}^{2} 5-\mathrm{FU}$ as i.v. and 2,400 $\mathrm{mg} / \mathrm{m}^{2} \mathrm{micro}-$ pump in ivgtt for $46 \mathrm{~h}$; one course was for two weeks and at least three courses were needed; $5 \mathrm{mg} / \mathrm{kg}$ bevacizumab was administered in the observation group (bevacizumab, Avastin $^{\circledR}, 100 \mathrm{mg} / 4 \mathrm{ml}$; Yangze Pharma, Taizhou, China); i.v. for the first time for no less than $1.5 \mathrm{~h}$, and i.v. for the second time to be finished within $1 \mathrm{~h}$, it could be finished within $0.5 \mathrm{~h}$ if patients showed good tolerance. Bevacizumab was stopped after i.v. once a day for two weeks, and patients with adverse effects of nausea and vomiting were treated by rehydration and parenteral nutrition support.

Observation index and evaluation criteria. In the two groups, follow-up period was 5-40 months, and the median time was
30 months. Treatment effects and the incidence of adverse drug reactions were compared. The therapeutic effective evaluation was divided into complete remission (CR), partial remission (PR), stable disease (SD), progressive disease (PD) according to the Criteria for the Evaluation of Therapeutic Effect of Solid Carcinoma (10). Objective response rate (ORR) is calculated as $\mathrm{ORR}=(\mathrm{CR}+\mathrm{PR}) /$ total cases $\times 100 \%$, disease control rate $(\mathrm{DCR})$ as $\mathrm{DCR}=(\mathrm{CR}+\mathrm{PR}+\mathrm{SD}) /$ total cases $\times 100 \%$. Disease-free survival (DFS), the recurrence rates and the survival rates were compared. VEGF expression of serum before and after treatment were compared by ELISA method. ELISA kits were from Sigma-Aldrich (St. Louis, MO, USA). Manual steps were followed strictly. Positive expressions of VEGF in the samples during the surgery were compared by immunohistochemical staining method, and brown-yellow suggested positivity. On each section, different 9 fields of view were chosen randomly at high-power (x400), and 100 cells were counted in each field. Semi-quantitative scoring method was adopted. According to the ratio of positive cells in every section: 0 , the positive cells <5\%; 1, 5-25\%; 2, 26-50\%; 3, 51-75\%; and 4, more than $75 \%$ positivity. The cell staining: When cells were colorless, score 0 ; when light yellow, score 1; brown yellow, score 2; and brown, score 3 . Total scores were added by these two scores; $\leq 3$ suggested that it was negative; $4-5$ that it was positive; and $\geq 6$ strongly positive.

Statistical analysis. SPSS 20.0 (IBM SPSS, Armonk, NY, USA) software was used for statistical analysis and measurement data were expressed by the mean \pm standard deviation. Comparisons among groups were analyzed by independent samples t-test; comparisons within groups underwent paring t-test; countable data are expressed by the rate and analyzed by $\chi^{2}$ test; ordinal data underwent rank-sum test; survival periods were analyzed by Kaplan-Meier method and log-rank $\chi^{2}$ test; $p<0.05$ indicated that the difference was statistically significant.

\section{Results}

Comparisons of treatment effects. ORR and DCR of the observation group were significantly higher than those of the control group, and the differences had statistical significance $(\mathrm{p}<0.05)$ (Table I).

Comparisons of adverse reaction rates. Adverse reaction rate of the observation group was lower than that of the 
Table II. Comparisons of adverse reaction rates [cases, $\mathrm{n}(\%)$ ].

\begin{tabular}{|c|c|c|c|c|c|c|c|}
\hline Groups & Cases & $\begin{array}{c}\text { Liver and } \\
\text { kidney damage }\end{array}$ & $\begin{array}{c}\text { Severe diarrhea } \\
\text { and vomiting }\end{array}$ & $\begin{array}{l}\text { Bone marrow } \\
\text { transplant }\end{array}$ & Infection & $\begin{array}{l}\text { Electrolyte } \\
\text { disturbance }\end{array}$ & $\begin{array}{c}\text { Overall } \\
\text { incidence }\end{array}$ \\
\hline Control & 46 & 3 & 3 & 2 & 2 & 3 & $13(28.3)$ \\
\hline Observation & 46 & 1 & 1 & 1 & 1 & 1 & $5(10.9)$ \\
\hline & & & & & & & 4.420 \\
\hline P-value & & & & & & & 0.036 \\
\hline
\end{tabular}

Table III. Comparisons of VEGF expressions in serum and positive expressions in tissue VEGF.

\begin{tabular}{|c|c|c|c|c|c|c|}
\hline Groups & Cases & $\begin{array}{l}\text { VEGF before the } \\
\text { operation }(\mathrm{pg} / \mathrm{ml})\end{array}$ & $\begin{array}{l}\text { Follow-up } \\
\text { VEGF }\end{array}$ & $\begin{array}{l}\text { Stain negative } \\
\text { in tissue VEGF }\end{array}$ & Positive & $\begin{array}{l}\text { Strong } \\
\text { positive }\end{array}$ \\
\hline Control & 46 & $422.3 \pm 32.2$ & $67.4 \pm 19.8$ & $6(13.0)$ & $24(52.2)$ & $16(34.8)$ \\
\hline Observation & 46 & $418.2 \pm 31.3$ & $241.8 \pm 26.7$ & $8(17.4)$ & $18(39.1)$ & $20(43.5)$ \\
\hline t-test & & 0.125 & 86.235 & 1.587 & 1.587 & 1.587 \\
\hline P-value & & 0.869 & $<0.001$ & 0.452 & 0.452 & 0.452 \\
\hline
\end{tabular}

VEGF, vascular endothelial growth factor.

control group, and the difference had statistical significance $(\mathrm{p}<0.05)$ (Table II).

Comparisons of DFS, recurrence rates and survival rates. In the observation group, DFS was prolonged (38.6 vs. 30.5 months, log-rank $\left.\chi^{2}=8.234, \mathrm{p}=0.002\right)$, the recurrence rate reduced [13.0\% (6/46) vs. $\left.30.4 \%(14 / 46), \chi^{2}=4.089, \mathrm{p}=0.043\right]$, and the survival rate improved $[91.3 \%(42 / 46)$ vs. $76.1 \%(35 / 46)$, $\left.\chi^{2}=3.903, p=0.048\right]$. The differences were statistically significant $(\mathrm{p}<0.05)$ (Fig. 1).

Comparisons of VEGF expression in serum and positive expressions in tissue VEGF. VEGF expressions was lower in both groups but the VEGF expression in observation group was significantly lower than that in the control group. The difference was statistically significant $(\mathrm{p}<0.05)$. There was no statistical difference in comparisons of positive expressions in tissue VEGF ( $\mathrm{p}>0.05$ ) (Table III).

\section{Discussion}

VEGF (vascular permeability factor), is a highly specific tissue factor and the dimer is composed of two different subunits. It increases angiogenesis by promoting endothelial cell proliferation and provides nutrition for tumor cells. Moreover, it can inhibit antigen-presenting function of dendritic cells and reduce immunogenic functions of T-cells and B-cells, which leads to immune escape of colorectal neoplasms and incomplete cell clearance of residual tumor cells which are important factors causing recurrence (11). Sustainable expression in CRC can be taken as an effective target for CRC treatment. VEGFR, a protease-activated receptor, can maintain the growth and proliferation of cells. Its excessive activation will lead to rapid proliferation and metastasis of cancer cells and inhibit apoptosis of cancer cells (12).

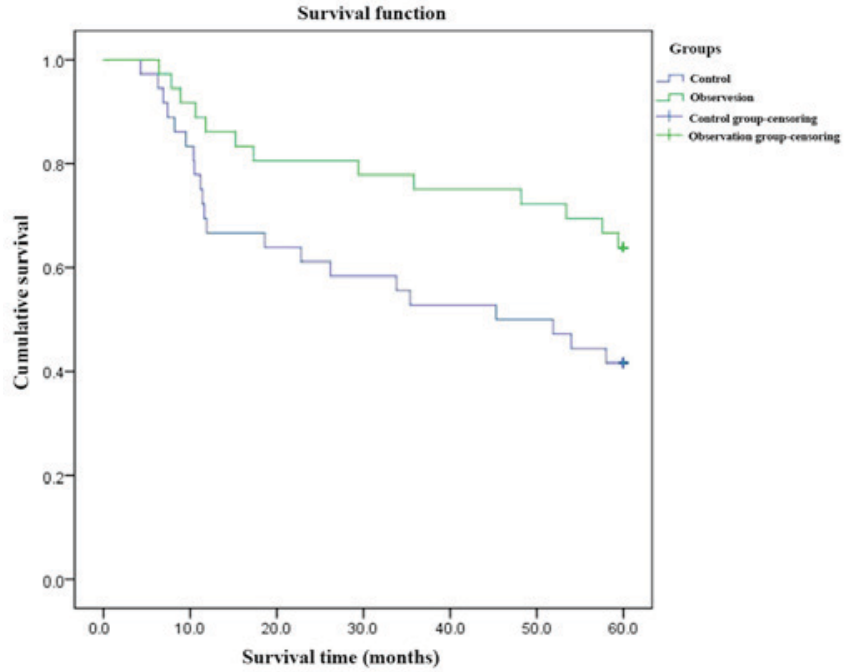

Figure 1. Comparisons of disease-free survival (DFS) in the groups.

VEGF and its receptor, VEGFR, participates in genesis and development of colorectal neoplasms and plays an important role in angiogenesis. Its high expression can stimulate angiogenesis, which is the basis of recurrence and metastasis of colorectal neoplasms (13). Detecting its expression can be an important marker of recurrence and prognosis of CRC (14).

This study concluded that VEGF expressions of follow-up serum in the two groups were lower, and VEGF expression of the control group was significantly lower than that of the observation group, and the difference was statistically significant. The difference of comparison of positive degrees in tissue VEGF had no statistical significance, and the positive rate was $82.6 \%(38 / 46)$ vs. $87.0 \%(40 / 46)$. In the observation group, VEGF expressions of follow-up serum decreased obviously, and it was closely related to treatment effects 
and survival outcomes. ORR and DCR of the observation group were significantly higher than those of the control group; the incidence of adverse reaction was lower; DFS was prolonged (38.6 vs. 30.5 months); the recurrence was reduced (13.0 vs. $30.4 \%$ ); the survival rate improved (91.3 vs. $76.1 \%$ ); the differences had statistical significance. These results suggested the safety and effectiveness of bevacizumab in chemotherapy after early CRC operation.

The mechanisms of bevacizumab targeting therapy include: i) Interference with tumor vessels (15): it breaks binding and activation directly, regulates or inhibits vasculature of tumors and prevents proliferation of tumor vessels. ii) Inhibit tumor differentiation (11): Tumor differentiation factors can operate in the micro-environment of vessel endothelium in the human body and produce angiogenesis effects; bevacizumab can inhibit secretion of tumor differentiation factors effectively and control the formation of new blood vessels from the source, such as cellular hypoxia to cause apoptosis, prevents normalization process of pseudo-vessels. iii) Antitumor effects (16): Bevacizumab reduces tumor interstitial pressure, decrease tumor vascular bed, change permeability, reduce seepage and make chemotherapeutic drugs released into the tumor cells more effective. iv) Inhibit the growth of cancer stem cells (CSC) (17): It can inhibit the microenvironment of $\mathrm{CSC}$ for growth, inhibit the activity of $\mathrm{ABC}$ transporter and block signaling transduction.

As suggested above, after treating early CRC with bevacizumab targeting therapy, VEGF expressions is reduced; treatment effects improve; adverse drug reaction is reduced; survival period is prolonged; the recurrence is lower; the survival rate improves. Therefore, it has good application values. However, because the sample size was small and the follow-up time was short, further observation and verification is needed.

\section{References}

1. Yung KW, Yung TT, Chung CY, Tong GT, Liu Y, Henderson J, Welbeck D and Oseni S: Principles of cancer staging. Asian Pac J Surg Oncol 1: 1-16, 2015.

2. Zheng YF, Tan LK, Tan BH, Sterling H and Kane R: Principles of surgical oncology. Asian Pac J Surg Oncol 1: 17-26, 2015.

3. Nasir A, Reising LO, Nedderman DM, Fulford AD, Uhlik MT, Benjamin LE, Schade AE and Holzer TR: Heterogeneity of vascular endothelial growth factor receptors $1,2,3$ in primary human colorectal carcinoma. Anticancer Res 36: 2683-2696, 2016.

4. Cabart M, Frénel JS, Campion L, Ramée JF, Dupuis O, Senellart H, Hiret S, Douillard JY and Bennouna J: Bevacizumab efficacy is influenced by primary tumor resection in first-line treatment of metastatic colorectal cancer in a retrospective multicenter study. Clin Colorectal Cancer 7: 15-16, 2016.
5. Nagasaka T, Mishima H, Sawaki A, Shimokawa M, Inukai M, Shinozaki K, Tanioka H, Nasu J, Nishina T, Hazama S, et al: Protocol of a randomised phase III clinical trial of sequential capecitabine or 5-fluorouracil plus bevacizumab (Cape/5-FU-Bmab) to capecitabine or 5-fluorouracil plus oxaliplatin plus bevacizumab (CapeOX/mFOLFOX6-Bmab) versus combination CapeOX/mFOLFOX6-Bmab in advanced colorectal cancer: the C-cubed (C3) study. BMJ Open 6: e011454, 2016

6. Ocvirk J, Moltara ME, Mesti T, Boc M, Rebersek M, Volk N, Benedik J and Hlebanja Z: Bevacizumab plus chemotherapy in elderly patients with previously untreated metastatic colorectal cancer: single center experience. Radiol Oncol 50: 226-231, 2016

7. Silva GL, de Moura EG, Bernardo WM, Leite de Castro V, Morais C, Baba ER and Safatle-Ribeiro AV: Endoscopic versus surgical resection for early colorectal cancer-a systematic review and meta-analysis. J Gastrointest Oncol 7: 326-335, 2016.

8. Probst A and Messmann H: Diagnosis and endoscopic treatment of early colorectal cancer. MMW Fortschr Med 158: 47-49, 2016 (In German).

9. Reggiani Bonetti L, Di Gregorio C, De Gaetani C, Pezzi A, Barresi G, Barresi V, Roncucci L and Ponz de Leon M: Lymph node micrometastasis and survival of patients with stage I (Dukes' A) colorectal carcinoma. Scand J Gastroenterol 46: 881-886, 2011.

10. Wolchok JD, Hoos A, O'Day S, Weber JS, Hamid O, Lebbé C, Maio M, Binder M, Bohnsack O, Nichol G, et al: Guidelines for the evaluation of immune therapy activity in solid tumors: immune-related response criteria. Clin Cancer Res 15: 7412-7420, 2009.

11. Verdaguer H, Tabernero J and Macarulla T: Ramucirumab in metastatic colorectal cancer: Evidence to date and place in therapy. Ther Adv Med Oncol 8: 230-242, 2016.

12. Gasser $M$ and Waaga-Gasser AM: Therapeutic antibodies in cancer therapy. Adv Exp Med Biol 917: 95-120, 2016.

13. Suenaga M, Mashima T, Kawata N, Wakatsuki T, Horiike Y, Matsusaka S, Dan S, Shinozaki E, Seimiya H, Mizunuma N, et al: Serum VEGF-A and CCL5 levels as candidate biomarkers for efficacy and toxicity of regorafenib in patients with metastatic colorectal cancer. Oncotarget 7: 34811-34823, 2016.

14. Zong S, Li H, Shi Q, Liu S, Li W and Hou F: Prognostic significance of VEGF-C immunohistochemical expression in colorectal cancer: a meta-analysis. Clin Chim Acta 458: 106-114, 2016.

15. Yue GG, Kwok HF, Lee JK, Jiang L, Wong EC, Gao S, Wong HL, Li L, Chan KM, Leung PC, et al: Combined therapy using bevacizumab and turmeric ethanolic extract (with absorbable curcumin) exhibited beneficial efficacy in colon cancer mice. Pharmacol Res 111: 43-57, 2016.

16. Michl M, Stintzing S, Fischer von Weikersthal L, Decker T, Kiani A, Vehling-Kaiser U, Al-Batran SE, Heintges T, Lerchenmueller C, Kahl C, et al; FIRE-3 Study Group: CEA response is associated with tumor response and survival in patients with KRAS exon 2 wild-type and extended RAS wild-type metastatic colorectal cancer receiving first-line FOLFIRI plus cetuximab or bevacizumab (FIRE-3 trial). Ann Oncol 27: 1565-1572, 2016.

17. Yoshida M, Takagane A, Miyake Y, Shimada K, Nagata N, Sato A, Ogata Y, Fukunaga M, Otsuka K, Takahashi T, et al: A phase II study of third-line combination chemotherapy with bevacizumab plus S-1 for metastatic colorectal cancer with mutated KRAS (SAVIOR Study). Oncology 91: 24-30, 2016. 